\title{
Detection of "Xisco" gene for identification of Streptococcus pneumoniae isolates
}

\author{
Francisco Salvà-Serra \\ University of Gothenburg \\ Gwendolyn Connolly \\ Technological University Dublin \\ Edward Moore \\ University of Gothenburg, erbmoore@ccug.se
}

See next page for additional authors

Follow this and additional works at: https://arrow.tudublin.ie/scschbioart

Part of the Biology Commons, and the Medicine and Health Sciences Commons

\section{Recommended Citation \\ Francisco Salvà-Serra, Gwendolyn Connolly, Edward R.B. Moore, Lucia Gonzales-Siles, Detection of "Xisco" gene for identification of Streptococcus pneumoniae isolates, Diagnostic Microbiology and Infectious Disease, Volume 90, Issue 4, 2018,Pages 248-250, ISSN 0732-8893, DOI: 10.1016/ j.diagmicrobio.2017.12.003.}

This Article is brought to you for free and open access by the School of Biological Sciences at ARROW@TU Dublin. It has been accepted for inclusion in Articles by an authorized administrator of ARROW@TU Dublin. For more information, please contact arrow.admin@tudublin.ie, aisling.coyne@tudublin.ie,gerard.connolly@tudublin.ie.

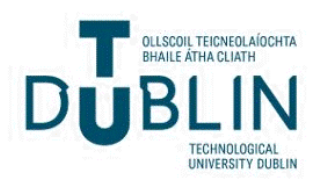


Authors

Francisco Salvà-Serra, Gwendolyn Connolly, Edward Moore, and Lucia Gonzales-Siles

This article is available at ARROW@TU Dublin: https://arrow.tudublin.ie/scschbioart/310 


\title{
Detection of "Xisco" gene for identification of Streptococcus pneumoniae isolates
}

\author{
Francisco Salvà-Serra $^{\text {a,b,c,d }}$, Gwendolyn Connolly ${ }^{\text {b,e }}$, Edward R.B. Moore ${ }^{\text {a,b,c,* }}$, Lucia Gonzales-Siles ${ }^{\text {a,b,c }}$ \\ a Department of Infectious Diseases, Institute of Biomedicine, Sahlgrenska Academy, University of Gothenburg, Gothenburg, Sweden \\ ${ }^{\mathrm{b}}$ Culture Collection University of Gothenburg (CCUG), Sahlgrenska Academy, University of Gothenburg, Sweden \\ c Centre for Antibiotic Resistance Research (CARe), University of Gothenburg, Gothenburg, Sweden \\ ${ }^{\mathrm{d}}$ Microbiology, Department of Biology, University of the Balearic Islands, Palma de Mallorca, Spain \\ e School of Biological Sciences, Dublin Institute of Technology, Dublin, Ireland
}

\section{A R T I C L E I N F O}

\section{Article history:}

Received 21 September 2017

Received in revised form 6 December 2017

Accepted 6 December 2017

Available online 15 December 2017

\section{Keywords:}

"Xisco" gene

Streptococcus pneumoniae

Pneumococcus

Identification

Mitis group

PCR

\begin{abstract}
A B S T R A C T
We describe a PCR-assay differentiating Streptococcus pneumoniae from closely-related species of the Mitis group of the genus Streptococcus and identification of pneumococcus clinical isolates, based on the "Xisco" gene discriminatory marker. The complete "Xisco" gene sequence was observed in all S. pneumoniae genomes analyzed and absent in all non-pneumococcus genomes.
\end{abstract}

(C) 2017 Elsevier Inc. All rights reserved.
Streptococcus pneumoniae (pneumococcus) is a significant global cause of serious human infections, including pneumonia, septicemia and meningitis, causing more than one million deaths and approximately fifteen million disease episodes annually (O'Brien et al., 2009). Current methods for identifying S. pneumoniae include characterization of bile solubility, optochin susceptibility, colony morphology, metabolic profiling and MALDI-TOF MS protein profiling (Dubois et al., 2013). However, these methods have problems discriminating S. pneumoniae from closely related, typically commensal species of the Mitis group of the genus Streptococcus (Dubois et al., 2013; Ikryannikova et al., 2013). The species of the Mitis group, within the viridans group streptococci (VGS) (Doern and Burnham, 2010) and delineated by 16S rRNA gene sequence clustering (Kawamura et al., 1995), share many genotypic and phenotypic similarities (Kilian et al., 2008). We have defined, from genome sequence data, and applied a discriminatory gene marker, the "Xisco" gene, for reliable differentiation of S. pneumoniae from the closely-related species, particularly S. pseudopneumoniae and S. mitis, of the Mitis group.

The "Xisco" gene was identified in the complete genome sequence of S. pneumoniae TIGR4 (Tettelin et al., 2001) (GenBank accession number: AE005672; locus tag: SP_1992). The gene is 666 bp in length, encoding a

\footnotetext{
* Corresponding author. Tel: +4631342 4696; Fax: +4631 829617.

E-mail address: erbmoore@ccug.se (E.R.B. Moore)
}

putative protein, predicted to be surface exposed, anchored to the cell wall. The protein sequence contains an LPXTG cell wall anchor motif and a domain of unknown function (Pfam family: DUF1542, Pfam accession number: pfam07564). In a S. pneumoniae pan-genome study wherein $44 \mathrm{~S}$. pneumoniae genomes were analyzed (Donati et al., 2010), the "Xisco" gene was described as highly conserved (average identity of the protein sequences: 99\%), present in S. pneumoniae and absent in the closely-related species of the Mitis group.

The sequence of the "Xisco" gene was extracted from the genome sequence of $S$. pneumoniae TIGR4. The gene sequence was aligned, using BLASTN v2.6.0+ (Altschul et al., 1997), against all genome sequences of S. pneumoniae that were available in GenBank (Benson et al., 2017) on $14^{\text {th }}$ March $2015(n=327)$ plus the S. pneumoniae type strain, NCTC $7465^{\mathrm{T}}$ (GenBank accession number: LN831051). These 328 genome sequences of $S$. pneumoniae represent 48 different serotypes; 36 of the strains were listed as non-serotypeable. Further analyses with BLASTN v2.6.0 + were carried out on all genome sequences assigned to 14 other species of the Mitis group that were available in GenBank on $28^{\text {th }}$ November 2017 ( $n=305$ ), including those for the type strains of S. australis, S. cristatus, S. dentisani, S. gordonii, S. infantis, S. massiliensis, S. mitis, S. oralis, S. parasanguinis, S. peroris, S. pseudopneumoniae, $S$. sanguinis, S. sinensis and S. tigurinus (Jensen et al., 2016). The taxonomic status of each of the 633 genome sequences (pneumococcus and nonpneumococcus) was confirmed by determining average nucleotide 


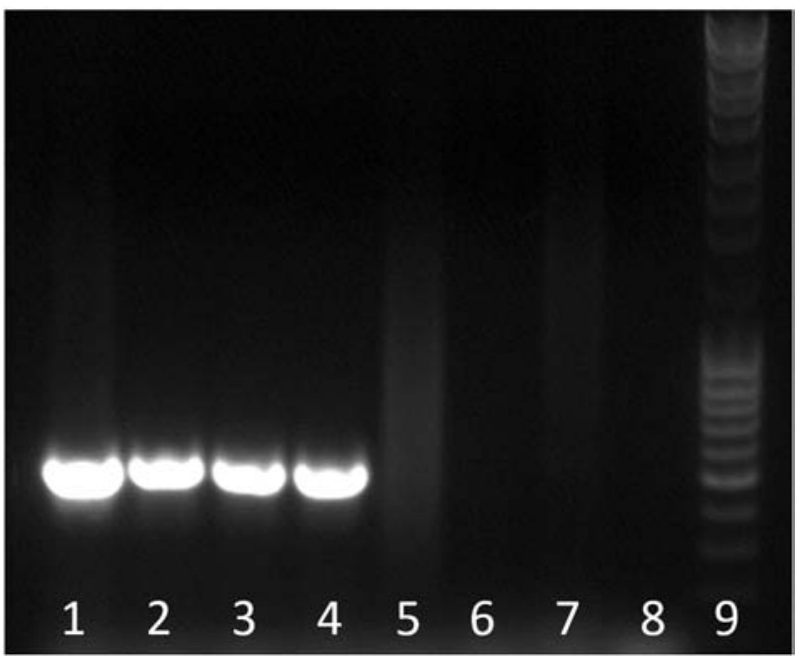

Fig. 1. PCR-amplification products of the "Xisco" gene (548 bp), obtained by use of the Spne-CW-F2 and Spne-CW-R primers. Lanes 1-4, S. pneumoniae reference strains CCUG 28588 ${ }^{\mathrm{T}}$, CCUG 6798, CCUG 12129 and CCUG 34199; lane 5, S. mitis CCUG $31611^{\mathrm{T}}$; lane 6, S. oralis CCUG $31611^{\mathrm{T}}$; lane 7, S. pseudopneumoniae CCUG $31611^{\mathrm{T}}$; lane 8 , negative control; lane 9, ladder (100-5000 bp).

identities, based on BLAST (ANIb) (Goris et al., 2007), using JSpeciesWS (Richter et al., 2016), against the genome sequence of S. pneumoniae NCTC $7465^{\mathrm{T}}$. Analyses revealed that the "Xisco" gene is present in all of the 328 genome sequences of $S$. pneumoniae (minimal query cover: 91\%; minimal identity: 96\%), that it is absent in 303 nonpneumococcus genomes and that only a fragment of the sequence is present in two non-pneumococcal genome sequences: S. mitis DD26 and S. pseudopneumoniae 163_SPSE (GenBank accession numbers: KQ970285 and JVRR00000000, respectively), with 93\% similarity over $63 \%$ of gene length. These results demonstrate the "Xisco" gene to be

Table 1

"Xisco" gene PCR-amplification results for type strains of $S$. pneumoniae, S. pseudopneumoniae, S. mitis and 25 clinical isolates.

\begin{tabular}{|c|c|c|c|}
\hline Organism & Strain & "Xisco" gene PCR & $\operatorname{ANIb}(\%)^{*}$ \\
\hline S. mitis & CCUG $31611^{\mathrm{T}}$ & - & 91.3 \\
\hline S. mitis & CCUG 63687 & - & 91.0 \\
\hline S. mitis & CCUG 69183 & - & 91.5 \\
\hline S. oralis & CCUG $13229^{\mathrm{T}}$ & - & 85.4 \\
\hline S. oralis & CCUG 35754 & - & 85.3 \\
\hline S. oralis & CCUG 62648 & - & 85.5 \\
\hline S. pseudopneumoniae & CCUG $49455^{\mathrm{T}}$ & - & 94.1 \\
\hline S. pseudopneumoniae & CCUG 62647 & - & 94.2 \\
\hline S. pseudopneumoniae & CCUG 63747 & - & 94.1 \\
\hline S. pneumoniae & CCUG $28588^{\mathrm{T}}$ & + & 99.9 \\
\hline S. pneumoniae & CCUG 1350 & + & 98.3 \\
\hline S. pneumoniae & CCUG 6798 & + & 98.4 \\
\hline S. pneumoniae & CCUG 7206 & + & 98.3 \\
\hline S. pneumoniae & CCUG 11780 & + & 98.2 \\
\hline S. pneumoniae & CCUG 32672 & + & 98.4 \\
\hline S. pneumoniae & CCUG 33774 & + & 98.4 \\
\hline S. pneumoniae & CCUG 35180 & + & 98.4 \\
\hline S. pneumoniae & CCUG 35229 & + & 98.5 \\
\hline S. pneumoniae & CCUG 35272 & + & 98.2 \\
\hline S. pneumoniae & CCUG 35561 & + & 98.5 \\
\hline S. pneumoniae & CCUG 36618 & + & 98.4 \\
\hline S. pneumoniae & CCUG 36800 & + & 98.4 \\
\hline S. pneumoniae & CCUG 45673 & + & 98.3 \\
\hline S. pneumoniae & CCUG 63093 & + & 98.3 \\
\hline S. pneumoniae & CCUG 63665 & + & 98.4 \\
\hline S. pneumoniae & CCUG 68718 & + & 98.2 \\
\hline S. pneumoniae & CCUG 69380 & + & 98.4 \\
\hline S. pneumoniae & CCUG 69381 & + & 98.3 \\
\hline S. pneumoniae & CCUG 69382 & + & 98.3 \\
\hline
\end{tabular}

* ANIb similarities to S. pneumoniae NCTC $7465^{\mathrm{T}}$, calculated with JSpeciesWS. Cut-off value of $95 \%$ is considered for S. pneumoniae identification. an excellent marker for distinguishing S. pneumoniae from closelyrelated species.

Specific PCR-amplification primers for the "Xisco" gene sequence were designed: forward primer, Spne-CW-F2 (5'-TGA CGA TTC TAG GAA AAG ATA CAG-3'); and reverse primer, Spne-CW-R (5'-AGC AGG TGA CTG GTA GGT AAC-3’). In silico sequence analyses predicted that the primers Spne-CW-F2 and Spne-CW-R would yield a PCRamplification product from all 328 analyzed genome sequences of S. pneumoniae. In silico analyses predicted, further, that no PCRamplification would be obtained from any of the 305 nonpneumococcus genome sequences of the Mitis group.

Amplification-primers were synthsized and tested on reference strains; four strains of S. pneumoniae, CCUG $28588^{\mathrm{T}}$, CCUG 6798, CCUG 12129 and CCUG 34199, were used as positive controls, while the type strains of the closest phylogenetic relatives of $S$. pneumoniae in the Mitis group, S. pseudopneumoniae CCUG $49455^{\mathrm{T}}$, S. mitis CCUG $31611^{\mathrm{T}}$ and S. oralis CCUG $13229^{\mathrm{T}}$, were used as negative controls (Fig. 1). The reaction mixture for PCR-assays comprised 0.1 to $10 \mathrm{ng}$ of DNA template, 1X Taq PCR Master Mix (Qiagen, Hilden, Germany), $1 \mu \mathrm{M}$ concentration of each amplification-primer, in a total volume of $25 \mu \mathrm{L}$. The PCR conditions were as follows: initial denaturation at $95{ }^{\circ} \mathrm{C}$ for $5 \mathrm{~min}$; followed by 30 cycles of denaturation at $95{ }^{\circ} \mathrm{C}$ for $30 \mathrm{~s}$, primerannealing at $55{ }^{\circ} \mathrm{C}$ for $30 \mathrm{~s}$, and primer-extension at $72{ }^{\circ} \mathrm{C}$ for $90 \mathrm{~s}$; and a final elongation-period at $72{ }^{\circ} \mathrm{C}$ for $5 \mathrm{~min}$. PCR-products were resolved by electrophoresis in $1 \%$ agarose gels, in E-buffer, at $70 \mathrm{~V}$ for 20 min and stained with GelRed ${ }^{\mathrm{TM}}$ (Biotium, CA, USA).

The presence or absence of the "Xisco" gene was determined in the type strains of 15 species of the Mitis group, and in 25 clinical isolates of S. pneumoniae ( $n=19)$, S. pseudopneumoniae $(n=2)$, S. mitis $(n=$ 2 ) and S. oralis $(n=2)$, with determined whole-genome sequences, collected in Sweden, Denmark, France, Spain and the USA, in different years, from 1971 to 2016 . The results were correlated to ANIb values of similarity against the genome sequence of S. pneumoniae NCTC $7465^{\mathrm{T}}$ (Table 1). The identifications of strains were confirmed by ANIb values of genome sequence similarities to reference type strains.

In conclusion, the proposed PCR-assay for detection of the "Xisco" gene is a reliable method for differentiation of $S$. pneumoniae from the closely-related species of the Mitis group. This assay is particularly constructive, albeit simple, when established protocols cannot definitively identify S. pneumoniae.

\section{Acknowledgments}

This work was supported by the Department of Clinical Microbiology, Sahlgrenska University Hospital and the European Commission: TAILORED-Treatment (project number 602860; www.tailoredtreatment.eu). FS-S and GC were supported by stipends for Basic and Advanced Research from the CCUG, through the Institute of Biomedicine, Sahlgrenska Academy, University of Gothenburg. GC was supported through the Erasmus + exchange program between the Dublin Institute of Technology and the University of Gothenburg.

\section{Declaration of interest}

Conflicts of interest: none.

\section{References}

Altschul SF, Madden TL, Schaffer AA, Zhang J, Zhang Z, Miller W, et al. Gapped BLAST and PSI-BLAST: a new generation of protein database search programs. Nucleic Acids Res 1997;25(17):3389-402.

Benson DA, Cavanaugh M, Clark K, Karsch-Mizrachi I, Lipman DJ, Ostell J, et al. GenBank. Nucleic Acids Res 2017;45(D1):D37-42.

Doern CD, Burnham CA. It's not easy being green: the viridans group streptococci, with a focus on pediatric clinical manifestations. J Clin Microbiol 2010;48(11):3829-35.

Donati C, Hiller NL, Tettelin H, Muzzi A, Croucher NJ, Angiuoli SV, et al. Structure and dynamics of the pan-genome of Streptococcus pneumoniae and closely related species. Genome Biol 2010;11(10):R107. 
Dubois D, Segonds C, Prere MF, Marty N, Oswald E. Identification of clinical Streptococcus pneumoniae isolates among other alpha and nonhemolytic streptococci by use of the Vitek MS matrix-assisted laser desorption ionization-time of flight mass spectrometry system. J Clin Microbiol 2013;51(6):1861-7.

Goris J, Konstantinidis KT, Klappenbach JA, Coenye T, Vandamme P, Tiedje JM. DNA-DNA hybridization values and their relationship to whole-genome sequence similarities. Int J Syst Evol Microbiol 2007;57(Pt 1):81-91.

Ikryannikova LN, Filimonova AV, Malakhova MV, Savinova T, Filimonova O, Ilina EN, et al. Discrimination between Streptococcus pneumoniae and Streptococcus mitis based on sorting of their MALDI mass spectra. Clin Microbiol Infect 2013;19(11):1066-71.

Jensen A, Scholz CF, Kilian M. Re-evaluation of the taxonomy of the Mitis group of the genus Streptococcus based on whole genome phylogenetic analyses, and proposed reclassification of Streptococcus dentisani as Streptococcus oralis subsp. dentisani comb. nov., Streptococcus tigurinus as Streptococcus oralis subsp. tigurinus comb. nov., and Streptococcus oligofermentans as a later synonym of Streptococcus cristatus. Int J Syst Evol Microbiol 2016;66(11):4803-20.
Kawamura Y, Hou XG, Sultana F, Miura H, Ezaki T. Determination of 16S rRNA sequences of Streptococcus mitis and Streptococcus gordonii and phylogenetic relationships among members of the genus Streptococcus. Int J Syst Evol Microbiol 1995;45(2): 406-8.

Kilian M, Poulsen K, Blomqvist T, Havarstein LS, Bek-Thomsen M, Tettelin H, et al. Evolution of Streptococcus pneumoniae and its close commensal relatives. PLoS One 2008; 3(7):e2683.

O'Brien KL, Wolfson LJ, Watt JP, Henkle E, Deloria-Knoll M, McCall N, et al. Burden of disease caused by Streptococcus pneumoniae in children younger than 5 years: global estimates. Lancet 2009;374(9693):893-902.

Richter M, Rossello-Mora R, Oliver Glockner F, Peplies J. JSpeciesWS: a web server for prokaryotic species circumscription based on pairwise genome comparison. Bioinformatics 2016;32(6):929-31.

Tettelin H, Nelson KE, Paulsen IT, Eisen JA, Read TD, Peterson S, et al. Complete genome sequence of a virulent isolate of Streptococcus pneumoniae. Science 2001; 293(5529):498-506. 